\title{
Curcumin promotes apoptosis in human lung adenocarcinoma cells through miR-186* signaling pathway
}

\author{
JIAN ZHANG $^{1 *}$, YONGPING DU $^{2 *}$, CHANGGUI WU $^{1 *}$, XINLING REN $^{1}$, XINYU TI $^{1}$, \\ JIERAN SHI $^{1}$, FENG ZHAO ${ }^{1}$ and HONG YIN $^{3}$ \\ Departments of ${ }^{1}$ Respiratory Medicine, ${ }^{2}$ Traditional Chinese Medicine, and ${ }^{3}$ Radiology, Xijing Hospital, \\ Fourth Military Medical University, No 15 Changlexi Road, Xi'an 710032, P.R. China
}

Received April 29, 2010; Accepted June 11, 2010

DOI: 10.3892/or_00000975

\begin{abstract}
Lung cancer is one of the leading causes of cancerrelated death worldwide. Curcumin has been reported to have an antitumor effect by inducing apoptosis and suppressing growth of tumor cells. However, the mechanism by which curcumin exerts its anti-cancer effect needs further research. The purpose of the present study was to identify a miRNAmediated mechanism which plays a role in the anti-cancer effects of curcumin. Alterations in miRNA expression were seen in curcumin-treated A549 cells, including significant downregulation of miRNA-186* expression by microarray analysis and real-time PCR. The miRNA-186* functions by overexpression or inhibition were investigated using biological assays in A549 cells. Additionally, caspase-10 was identified as a target of miRNA-186* using dual luciferase reporter assays and Western blot analysis. These results demonstrate that curcumin induces A549 cell apoptosis through a miRNA pathway. Also, miRNA-186* could serve as a potential gene therapy target in curcumin treatment. Furthermore, caspase-10 was shown to be a target of miR$186^{*}$ regulation.
\end{abstract}

\section{Introduction}

Lung cancer causes more cancer related deaths worldwide than prostate, breast, or colorectal cancer (1). The morbidity of non-small cell lung carcinoma (NSCLC) accounts for

Correspondence to: Dr Jian Zhang, Department of Respiratory Medicine or Dr Yin Hong, Department of Radiology, Xijing Hospital, The Fourth Military Medical University, No 15 Changlexi Road, Xi'an 710032, P.R. China

E-mail: zhangjian197011@yahoo.com

E-mail: yinnhong@yahoo.com

${ }^{*}$ Contributed equally

Abbreviations: miR, miRNA or microRNA; MTT, 3-(4,5dimethylthiazol-2-yl)-2,5-diphenyl-tetrazolium bromide; UTR, untranslated region

Key words: curcumin, A549 human lung adenocarcinoma cells, miRNA-186*, caspase-10, apoptosis
$80.4 \%$ of all lung cancer deaths (2). Because of its insidious onset the disease is usually not discovered until the later stages when patients have lost the opportunity for radical surgery following a confirmed diagnosis (3). Early diagnosis and low toxicity drugs are essential to achieving better treatment for lung cancer patients. Therefore, it is very important to select safe and effective natural compounds for use in the clinic (4).

Curcuma longa $\mathrm{L}$ is a plant that belongs to the Zingiberaceae family. Curcumin, which is extracted from the rhizomes of $C$. longa $\mathrm{L}$, is the major component of this plant (5). Curcumin has been reported to induce diverse pharmacological effects, including anti-inflammatory, antioxidant and anti-tumour activities (6). It has also been shown to suppress the activation of nuclear factor- $\kappa \mathrm{B}(\mathrm{NF}-\kappa \mathrm{B})$ signalling that is induced by various tumour promoters, including phorbol esters, tumour necrosis factor and hydrogen peroxide. More recently, several studies have shown that curcumininduced downregulation of $\mathrm{NF}-\kappa \mathrm{B}$ is mediated through the suppression of IкB kinase (IKK) activation $(7,8)$. This anti$\mathrm{NF}-\kappa \mathrm{B}$ activity of curcumin has been reported to be causally linked to apoptosis through the reduced expression of antiapoptotic players, such as survivin/BIRC5 and $\operatorname{Bcl} 2(9,10)$. However, there are few reports on the role that miRNAs may play in the anti-tumour effects of curcumin.

miRNAs are a class of short, highly conserved noncoding RNAs known to play essential roles in numerous developmental processes. miRNAs are transcribed as longer primary transcripts (pri-miRNA) that are sequentially processed by the RNase III-like enzymes, Drosha and Dicer $(11,12)$. Investigators have found that aberrant expression of miRNAs may play a critical role in tumorigenesis $(13,14)$. The expression of the let-7 family of miRNAs was downregulated in lung cancer and these miRNAs are considered tumour suppressor genes (15). In contrast, expression of the miR-17-92 cluster was increased in lung cancer and these miRNAs are considered to be oncogenes 'oncomirs' (16). The differential expression profile of miRNAs in lung cancer makes them new biomarker candidates for clinical diagnosis and prognosis (17).

In this study, microarray analysis was performed on A549 human lung adenocarcinoma cells treated with curcumin to identify which miRNAs are induced by this treatment. The results indicated that curcumin can suppress A549 cell proliferation and induce apoptosis through downregulation 
Table I. The primers used for stem-loop RT-PCR for miR-186*.

\begin{tabular}{ll}
\hline Primer & \multicolumn{1}{c}{ Sequence } \\
\hline U6 forward & 5'-GCTTCGGCAGCACATATACTAAAAT-3' \\
U6 reverse & 5'-CGCTTCACGAATTTGCGTGTCAT-3' \\
miR-186* RT & 5'-GTCGTATCCAGTGCGTGTCGTGGAGTCGGCAATTGCACTGGATACGACCCCAAA-3' \\
miR-186* forward & 5'-CCCGATAAAGCTAGATAACC-3' \\
miR-186* reverse & 5'-CAGTGCGTGTCGTGGAGT-3' \\
\hline
\end{tabular}

of miRNA-186* expression. Furthermore, caspase-10 was shown to be a target of miR-186*. Thus, we have demonstrated that curcumin promotes apoptosis in human lung adenocarcinoma cells through miR-186* signaling pathway.

\section{Materials and methods}

Cell culture. The A549 human lung adenocarcinoma cell line was cultured in the laboratory (obtained from the Academy of Military Medical Science, Beijing, China). Cells were cultured in RPMI-1640 medium supplemented with $10 \%$ (v/v) bovine calf serum, $1 \times 10^{5} \mathrm{U} / \mathrm{ml}$ penicillin and $100 \mathrm{mg} / \mathrm{l}$ streptomycin. Cells were grown at $37^{\circ} \mathrm{C}$ with $5 \% \mathrm{CO}_{2}$.

MTT assay. Cellular growth inhibition was assayed by the MTT method (18). A549 cells were seeded at a density of $5 \times 10^{3}$ cells/well in 96-well culture plates (Nunc, Roskilde, Denmark). A549 cells were treated with varying concentrations of curcumin (Sigma, St. Louis, MO) at different time intervals or transfected with $200 \mathrm{pM}$ of miR-186* inhibitor or inhibitor control. An MTT solution $(5 \mathrm{mg} / \mathrm{ml})$ was added and cells incubated at $37^{\circ} \mathrm{C}$ for an additional $4 \mathrm{~h}$. The supernatant in each well was carefully removed and formazan crystals were dissolved in DMSO for $10 \mathrm{~min}$ with shaking. The absorbance of each well was then read at $570 \mathrm{~nm}$ using an enzyme-linked immunosorbent assay reader. All experiments were performed in triplicate and numerical data are presented as mean $\pm \mathrm{SD}$. The concentration at which curcumin produced $50 \%$ inhibition of growth $\left(\mathrm{IC}_{50}\right)$ was calculated by the relative survival curve.

miRNA microarray. miRNA-enriched total RNA was isolated from curcumin-treated and untreated A549 cells with TRIzol reagent (Invitrogen, Carlsbad, CA). The miRNA fraction was further purified using the mirVana ${ }^{\mathrm{TM}}$ miRNA Isolation Kit (Ambion, Austin, TX). The isolated miRNAs were then labelled with $\mathrm{Hy} 5^{\mathrm{TM}}$ and $\mathrm{Hy} 3^{\mathrm{TM}}$ fluorescent label using the Mercury Array Power Labelling Kit (Exelon) and hybridised to the miRCURY ${ }^{\mathrm{TM}}$ LNA miRNA Array (v10.0, Exiqon) as described (19). Microarray images were acquired using a GenePix 4000B scanner (Axon Instruments, Union City, CA) and analysed with GenePix Pro 6.0 software (Axon Instruments) to perform median normalisation. Results were saved as Excel files.

Quantitative real-time PCR. Total RNA was extracted from A549 cells that were treated with different concentrations of curcumin using TRIzol (Invitrogen) and quantified by measuring absorbance at $260 \mathrm{~nm}$. Expression of mature miRNAs was assayed using stem-loop RT followed by realtime PCR analysis, as previously described (20). All reagents for stem-loop RT were obtained from Applied Biosystems (Foster City, CA). PCR products were analysed by $3 \%$ agarose gel electrophoresis. The relative amount of each miRNA was normalised to an individual U6 snRNA molecule. The fold-change for each miRNA in curcumin-treated cells relative to control (untreated) cells was calculated using the $2^{\Delta \Delta \mathrm{CT}}$ method (19), where $\Delta \Delta \mathrm{Ct}=\Delta \mathrm{Ct}$ curcumin treated $\Delta \mathrm{Ct}$ untreated and $\Delta \mathrm{Ct}=\mathrm{Ct}$ miRNA-Ct U6. PCR was performed in triplicate. The primers used for stem-loop RTPCR for miR-186* are listed in Table I.

FCM assay. miRNA-186* precursors, antisense inhibitors or controls were all purchased from Ambion. A549 cells were plated in 6 -well plates $\left(4 \times 10^{5}\right.$ cells/well) in antibiotic-free medium and transfected with 200 pmol of oligonucleotides using siPORT NeoFX buffer (Ambion) in accordance with the manufacturer's instructions. Forty-eight hours after transfection, apoptosis was measured by PI and Annexin V-FITC double-staining. Flow cytometry analysis was performed using Becton-Dickinson FACS-420 flow cytometry with an excitation wavelength of $488 \mathrm{~nm}$ and an emission wavelength of $525 \mathrm{~nm}$. All experiments were performed in triplicate.

Luciferase activity assay. The 3'UTR of human caspase-10 cDNA containing the putative target site for miR-186* was amplified by PCR using the following primers: 5'-GATATC GATAATCTGACATGCCTGG-3' and 5'-CTGCAGGATC CGGAGGTGTTACCATTTCT-3'. The PCR product was inserted into the $X b a \mathrm{I}$ site, immediately downstream of the luciferase gene in the pGL3-control vector (Promega, Madison, WI). A mutant version of caspase-10 with a 5 bp mutation within the 'seed region' was generated using the QuikChange II Site-Directed Mutagenesis Kit (Stratagene, La Jolla, CA). Wild-type and mutant inserts were confirmed by sequencing. Twenty-four hours before transfection, cells were plated at $1.5 \times 10^{5}$ cells/well in 24-well plates. The pGL3-caspace 10 3'UTR or pGL3-caspace 10-3'UTR mutant vectors (200 ng) and $80 \mathrm{ng}$ of pRL-TK (Promega) were co-transfected into cells along with miR-186* precursor (200 pmol) or control using Lipofectamine 2000 (Invitrogen) according to the manufacturer's protocol. Luciferase activity was measured $24 \mathrm{~h}$ after transfection using the Dual Luciferase Reporter Assay System (Promega). Firefly luciferase activity was normalised to Renilla luciferase activity for each transfected well. Independent experiments were performed in triplicate. 
$\rightarrow-$ concentration for $6 \mathrm{~h} \rightarrow-$ concentration for $12 \mathrm{~h}$

a
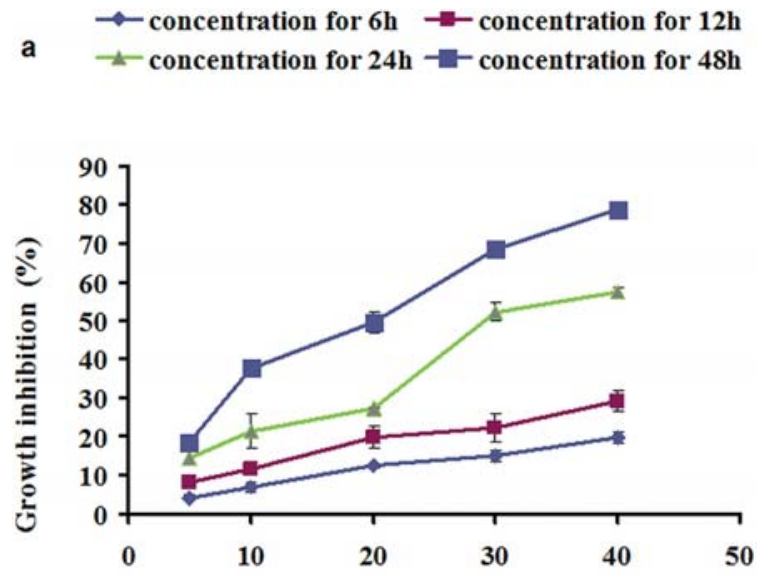

Concentration of $\mathrm{Cur}(\mu \mathrm{mol} / \mathrm{L})$

b
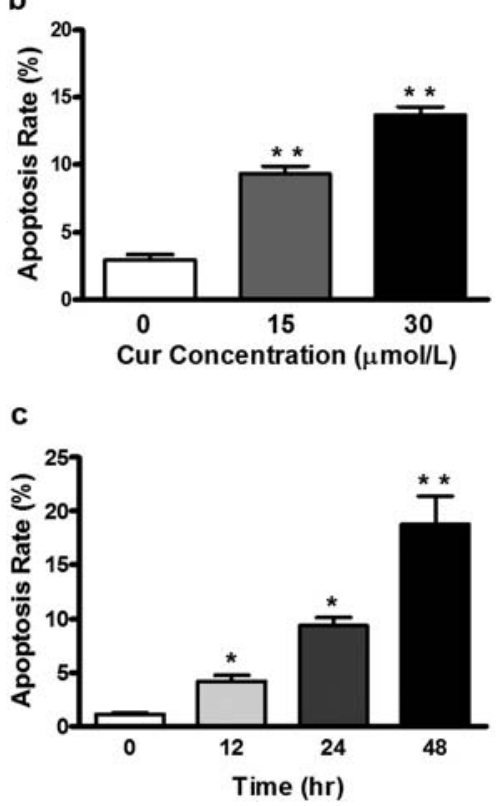

Figure 1. Curcumin treatment inhibits proliferation and induces apoptosis in A549 cells. (a) A549 cells were treated with the indicated concentrations of curcumin for the indicated times and MTT assays were performed. (b and c) Curcumin induces A549 cell apoptosis in a dose- and time-dependent manner. Cells were stained with Annexin V-FITC and PI and apoptosis assayed by flow cytometry. The percentage of apoptotic cells compared with control cells are shown $(n=3$, mean $\pm S D)$. Representative histograms are shown, ${ }^{*} \mathrm{P}<0.05,{ }^{* *} \mathrm{P}<0.01$ compared with control cells.

\section{Results}

Curcumin inhibits cell proliferation and induces A549 cell apoptosis. Curcumin has been shown to be anti-tumourigenic in different cancer cell types, including prostate cancer cells and human pituitary tumour cells $(21,22)$. The effect of curcumin treatment on the proliferation and apoptosis of A549 cells was determined by MTT and apoptosis assays, respectively. Curcumin suppressed A549 cell proliferation in a dose- and time-dependent manner (Fig. 1a). The halfmaximal inhibitory concentration (IC50) of curcumin that A549 cells could withstand for $48 \mathrm{~h}$ was $16.28 \mu \mathrm{M}$. Curcumin also induced A549 cell apoptosis in a dose- and timedependent fashion (Fig. 1b and c).

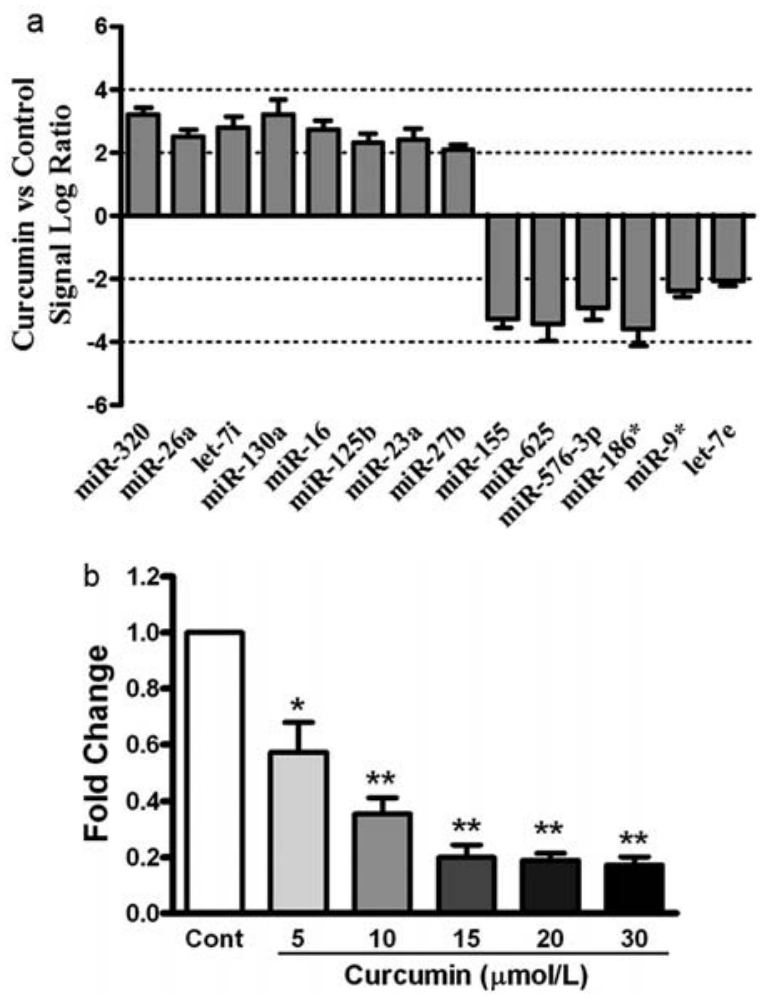

Figure 2. Alterations in miRNA expression in curcumin-treated A549 cells. (a) A549 cells were treated with curcumin $(15 \mu \mathrm{M})$ or $0.02 \%$ DMSO for $48 \mathrm{~h}$. Microarray analysis showed significant expression changes in a set of miRNAs after curcumin treatment. $\log _{2}$ values were adopted to compare miRNA expression changes. Those miRNAs with altered expression after curcumin treatment (at least a 2-fold increase or decrease in expression relative to DMSO-treated samples) are shown. (b) RT-PCR analysis of miR$186^{*}$ expression in cells treated with different concentrations of curcumin was used to validate the microarray results. Triplicate assays were performed for each RNA sample, and the relative amount of each miRNA was normalised to individual U6 snRNA. Data are shown as fold-change of miRNA levels in A549 cells treated with curcumin relative to untreated control cells $(n=3$, mean $\pm \mathrm{SD}),{ }^{*} \mathrm{P}<0.05,{ }^{* *} \mathrm{P}<0.01$, compared with control cells.

Curcumin treatment alters the expression profile of miRNAs in A549 cells. Although a limited number of miRNAs have been shown to regulate diverse cellular processes, there are few studies examining whether miRNA expression is changed in curcumin-treated human lung cancer cells. Cluster analysis was performed on the expression profiles of curcumin-treated $(15 \mathrm{mM})$ and DMSO control-treated samples. $\log _{2}$ values were used to compare changes in miRNA expression. Those miRNAs that were up- or downregulated by more than 2-fold after curcumin treatment were selected for further study. After $48 \mathrm{~h}$ of curcumin treatment, six miRNAs (miR-186*, miR-625, miR-576, miR-39, miR-9*, let7e) were downregulated, and eight miRNAs (miR-320, miRNA-26a, miR-16, miRNA-130a, miR-125b, miR-23a, miR-23b and let-7i) were upregulated when compared with DMSO control (Fig. 2a). miR-186*, in particular, was significantly downregulated with a $92.2 \%$ reduction in its levels after curcumin treatment. There are only a few reports linking miRNA-186 to tumorigenesis. In one of these, it was recently shown that the expression of miRNA-186 is higher in epithelial cancer cells than in normal cells (23). Thus, we suggest that miRNA-186* may play an oncogenic role in human lung cancer cells. 


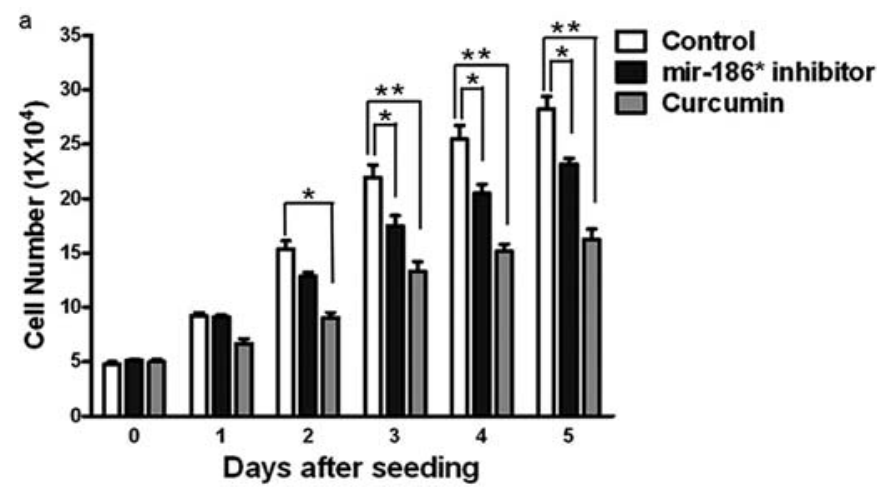

b

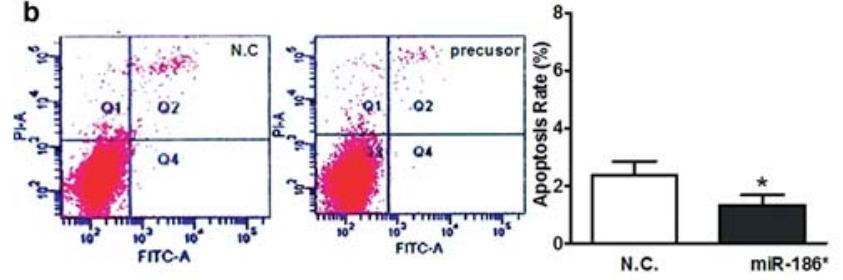

C

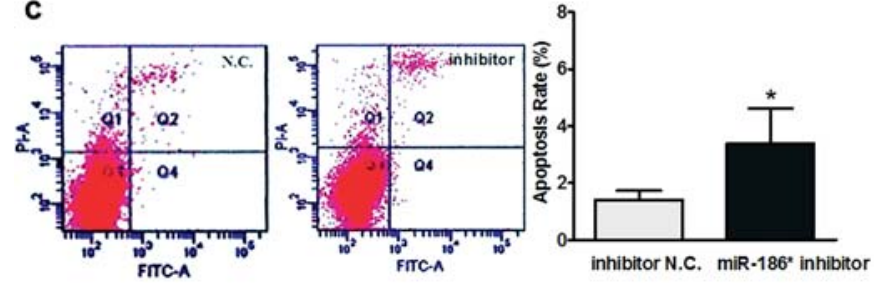

Figure 3. The inhibition of miR-186* blocks A549 proliferation and induces apoptosis. (a) A549 cells were transfected with 200 pmol of miR-186 inhibitor or inhibitor control or were treated with $15 \mu \mathrm{M}$ of curcumin. The data shown represent the mean $\pm \mathrm{SD}, \mathrm{n}=6,{ }^{*} \mathrm{P}<0.05,{ }^{* *} \mathrm{P}<0.01$. (b and $\mathrm{c}$ ) A549 cells were transfected with miR-186* precursor or precursor control and with miR-186* inhibitor or inhibitor control (200 pm) for $48 \mathrm{~h}$. Cells were stained with Annexin V-FITC and PI and apoptosis were measured by flow cytometry $(n=3$, mean $\pm S D)$. Representative histograms are shown, ${ }^{*} \mathrm{P}<0.05$ compared with control cells.

Quantitative real-time PCR (qRT-PCR) is generally considered the 'gold-standard' assay for measuring gene expression and is often used to confirm microarray data (24). We used qRT-PCR to determine whether there were changes in the expression of miRNA-186*, which was found to be significantly downregulated after curcumin treatment in the microarray experiments. The same total RNA preparation that was used for the microarray analysis was also used for quantitative real-time PCR analysis. Specific miRNAs were reverse-transcribed and PCR amplified in the ABI Prism 7600 Detection System (Applied Biosystems). Expression of U6 was used as an internal control. Values from the curcumin-treated and untreated groups were normalised to U6 values. Real-time PCR analysis confirmed that miRNA$186^{*}$ expression was decreased following treatment with different concentrations of curcumin, a finding that is consistent with the microarray results (Fig. 2b).

Inhibition of miRNA-186* suppresses A549 cells proliferation and induces apoptosis. Experiments examined whether miRNA-186* has a critical function in lung cancer cells. Cell proliferation was measured by MTT assay in A549 cells transfected with 200 pmol of miR-186* inhibitor or inhibitor control or treated with curcumin $(15 \mu \mathrm{M})$. A549 cell proliferation was found to be suppressed after curcumin treatment. In addition, A549 cells transfected with miR-186* inhibitor also exhibited greatly decreased proliferation when compared with the control groups after $72 \mathrm{~h}$ (Fig. 3a). These results indicate that miR-186* may play an oncogenic role in the development of lung cancer.

We hypothesised that miR-186* has a positive effect on A549 cell proliferation, at least in part, by modulating apoptosis. To test this hypothesis, we evaluated the antiapoptotic effect of the enforced expression of miR-186* in A549 cells. Cells were transfected with 200 pmol of miR-186* inhibitor or inhibitor control and with miR-186* precursor or precursor control for $48 \mathrm{~h}$ and cell apoptosis was measured. In these experiments, transfection of A549 cells with miRNA-186* precursor or miRNA-186* inhibitor caused statistically significant changes in the incidence of apoptosis in comparison to their respective control groups (Fig. 3b and c) $\left({ }^{*} \mathrm{P}<0.05\right)$. These results demonstrate that miR-186* plays a critical role in both the growth and apoptosis of lung cancer cells.

Prediction of miR-186* target gene. There are more than 700 putative target genes for miR-186* that are generated by Miranda. We classified these putative targets according to function. Target genes related to proliferation and apoptosis were screened first (Table II). We selected three target genes, including caspase-10, myc and bc19, which have well documented roles in proliferation and apoptosis. In verifying these targets, it was found that caspase-10 gave meaningful results (see below).

Caspase-10 is a target gene of miR-186*. The 3'UTR of caspase-10 contains a binding site for miR-186*. A caspase10-3'UTR mutant construct containing a mutation in the miR-186* 'seed region' binding site was generated (Fig. 4a). To assess whether miR $186^{*}$ directly regulates caspase- 10 expression, we constructed a luciferase reporter vector with the putative caspase 10-3'UTR target site for miR-186* downstream of the luciferase gene (pGL3-caspase 10-3'UTR). A mutant version of pGL3-caspase 10-3'UTR with a $5 \mathrm{bp}$ mutation within the seed region was also generated (pGL3mutcaspase 10-3'UTR). Luciferase reporter vector, alone or together with miR-186* precursor or precursor control, was transfected into A549 cells that weakly expressed miR-186*. A significant decrease in relative luciferase activity was noted when pGL3-caspase 10-3'UTR was co-transfected with miR-186 precursor but not with scrambled oligonucleotide. As expected, suppression was abolished by mutation of the 3'UTR miR-186* binding site (pGL3-mutcaspase 10-3'UTR), which disrupts the interaction between miR-186* and the caspase 10-3'-UTR (Fig. 4b and c).

Western blot analysis further confirmed the luciferase assay results. The protein expression of caspase-10 in curcumin-treated cells was increased compared with DMSO control-treated cells (Fig. 5a). In addition, miR-186* inhibitor and precursor were transfected into A549 cells and Western blot analysis was performed. Results showed that caspase-10 protein expression was increased in A549 cells transfected with the miR-186* inhibitor compared with control cells, 
Table II. Target genes of miRNA-186*.

\begin{tabular}{|c|c|c|}
\hline Target gene & Transcript & Target gene name \\
\hline ZNF20 & ENST00000320108 & Zinc finger protein 625 \\
\hline MCM3 & ENST00000229854 & DNA replication licensing factor MCM3 \\
\hline CRLF1 & ENST00000007403 & Cytokine receptor-like factor 1 precursor \\
\hline RAB28 & ENST00000338176 & Ras-related protein Rab-28 \\
\hline RAB32 & ENST00000367495 & Ras-related protein Rab-32 \\
\hline MYC & ENST00000377970 & MYC proto-oncogene protein \\
\hline C3orf10 & ENST00000256463 & Probable protein BRICK1 \\
\hline BCAR3 & ENST00000370244 & Breast cancer anti-estrogen resistance protein 3 \\
\hline COX17 & ENST00000261070 & Cytochrome $\mathrm{C}$ oxidase copper chaperone protein \\
\hline MARK2 & ENST00000315032 & Serine-protein kinase MARK2 \\
\hline CASP10 & ENST00000374650 & Fas-association death domain protein interleukin-1B-converting enzyme 2 \\
\hline MCM2 & ENST00000265056 & DNA replication licensing factor MCM2 \\
\hline MDC1 & ENST00000376406 & Mediator of DNA damage checkpoint protein 1 \\
\hline HES1 & ENST00000232424 & Transcription factor HES-1 \\
\hline IL25 & ENST00000329715 & Interleukin-25 precusor \\
\hline ZFP1 & ENST00000378686 & Zinc finger protein 1 homlog \\
\hline RFX5 & ENST00000290524 & DNA-binding protein RFX5 \\
\hline ARRB2 & ENST00000269260 & Beta-arrestin-2 \\
\hline ECE1 & ENST000002642405 & Endothelin-converting enzyme 1 \\
\hline BCL9 & ENST00000369243 & B-cell lymphoma 9 \\
\hline MCM5 & ENST00000216122 & DNA replication licensing factor MCM5 \\
\hline EIF2B5 & ENST00000273783 & Translation initiation factor eIF-2B subunit epsilon \\
\hline
\end{tabular}

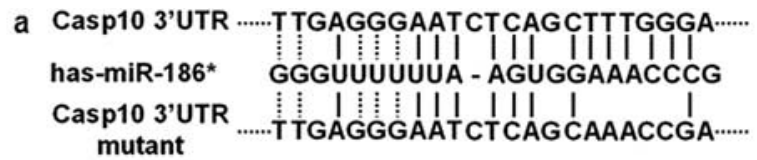

b
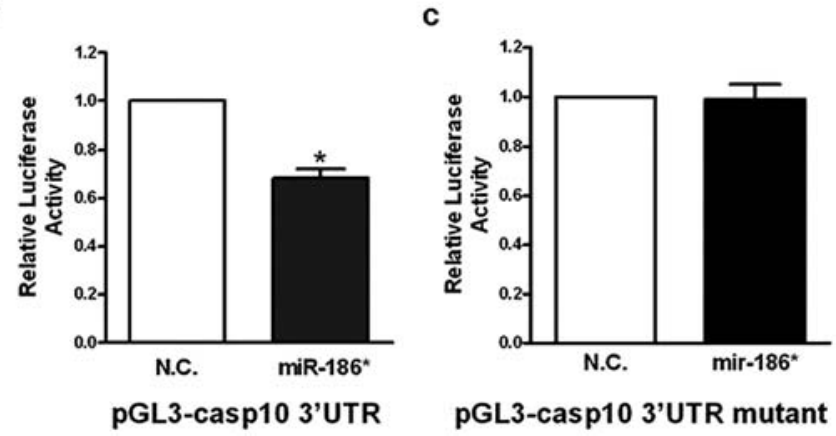

Figure 4. Validation of caspase-10 as a target of miR-186*. (a) As predicted in the MiRanda database, the $3^{\prime}$ UTR of caspase- 10 contains a binding site for miR-186*. A caspase 10-3'UTR mutant containing a mutation in the miR-186" 'seed region' binding site is also shown. (b and c) Dual luciferase assays were performed in A549 cells co-transfected with (b) pGL3-caspase 10-3'UTR or (c) pGL3-caspase 10-3'UTR mutant and miR-186* precursor or precursor control for $24 \mathrm{~h}$. Cells were collected and luciferase activity was determined. The results shown represent the mean \pm SD from 3 independent experiments, ${ }^{*} \mathrm{P}<0.05$.

whereas transfection with the miRNA-186* precursor led to decreased capase-10 protein expression (Fig. 5 b).

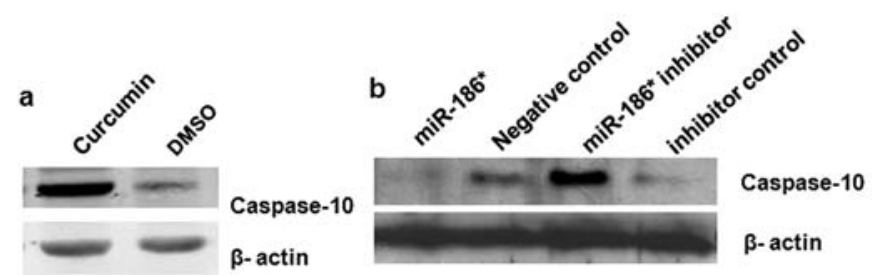

Figure 5. Caspase-10 is a target of miR-186*. (a) A549 cells were treated with curcumin $(15 \mu \mathrm{M})$ for $24 \mathrm{~h}$. The protein levels of caspase-10 were determined by Western blot analysis. $\beta$-actin protein levels were used as loading controls. (b) A549 cells were transfected with miR-186* precursor or precursor control and with miR-186* inhibitor or inhibitor control. Western blot analysis was performed to assess caspase-10 protein levels $24 \mathrm{~h}$ after transfection.

Collectively, these results demonstrate that curcumin induces apoptosis of the A549 lung cancer cell line through miR-186*, and that caspase-10 is a target of this miRNA.

\section{Discussion}

Many studies have demonstrated that the aberrant expression of miRNAs plays a role in tumorigenesis. miRNAs are predicted to modulate the expression of approximately one-third of human protein-coding genes and have a role in almost every genetic pathway (25-27). In addition, computational predictions indicate that each miRNA may target hundreds of genes, and that more than $50 \%$ of human 
protein-coding genes could be regulated by miRNAs (28). miRNA expression signatures seem to hold great promise for tumour characterisation and could be potential diagnostic and prognostic markers for cancer treatment (29). Curcumin has been reported to be a growth inhibitor and pro-apoptotic agent and has been shown to modulate cell signalling (30-32). However, very few publications have reported that curcumin suppresses cancer cell growth by a miRNA pathway. Only one study showed that curcumin alters miRNA expression in human pancreatic cells where it upregulates miRNA-22 and downregulates miRNA-199a* expression (33). In this study, the SP1 transcription factor and estrogens receptor 1 (ESR1) were identified as miRNA-22 targets. These results suggested that modulation of miRNA expression might be an important mechanism mediating the biological effects of curcumin. It is necessary to identify miRNA targets in different cancers treated with curcumin for the advancement of personalised medicine and cancer treatment.

Lung cancer causes high mobility and high mortality (1). In recent years, an increasing amount of research has investigated the role of miRNAs in lung cancer. It was demonstrated that miRNAs have somewhat better clinical utility in predicting the prognosis of patients with non-small cell lung cancer than mRNA-based signatures $(34,35)$. Let- 7 was the first miRNA discovered to play a role in lung cancer. It has been shown that let-7 expression levels are decreased in lung cancer cells, both in vitro and in vivo $(36,37)$. Some transcripts of the let-7 family that are significantly downregulated in lung tumours have been identified as tumour suppressors as a result of their ability to control several oncogenic pathways, including the RAS pathway (38). Furthermore, lung cancer patients with reduced let-7 expression were found to have significantly poorer prognosis after potentially curative resection. It was also found that abnormally expressed miRNAs in lung cancer might act as either tumour suppressors or oncogenes. Although emerging results clearly suggest that increased hsa-mir-155 and decreased hsa-let7a-2 expression are correlated with poor lung cancer patient survival (39), it is important to identify other potential miRNAs that play oncogenic or tumour suppressor roles in lung cancer.

A549 cells are generally recognised as the typical cell of human lung adenocarcinoma and have strong growth/ migration ability (40). Consistent with a previous report, our data showed that curcumin can inhibit A549 proliferation and induce apoptosis in a dose- and time-dependent manner (Fig. 1) (41). Microarray experiments showed that curcumin upregulated the expression of some miRNAs, such as miRNA-320, miRNA-130a and let-7i, and down-regulated others, such as miRNA-625 and miRNA-186*. miR-186*, in particular, was significantly downregulated with a $92.2 \%$ reduction in its levels after curcumin treatment. Real-time PCR confirmed the microarray experiments and showed that curcumin inhibits the expression of miR-186* in A549 cells. miR-186* and miR-186 originate from the same pre-miRNA. The level of miR-186 was found to be increased in cancer epithelial cells compared with normal cells (23). Moreover, miR-186 downregulates the expression of pro-apoptotic purinergic receptor, $\mathrm{P} 2 \mathrm{X} 7$, and treatment with miR-186 inhibitor increases P2X7 mRNA levels. Further analysis determined the presence of miR-186 target sites located in the P2X7 3'-UTR. miR-186* is located on chromosome 1p31.1. Before this report, there was no evidence to show that miR-186* was involved in cancer pathogenesis. Our results show that miR-186* is downregulated during curcumin-induced A549 cells apoptosis (Fig. 2). The inhibition of miR-186* not only inhibits A549 proliferation but also induces apoptosis (Fig. 3). At the same time, we found that the incidence of apoptosis caused by inhibition of miR$186^{*}$ is lower than that resulting from curcumin treatment (Fig. $3 b$ and c). We speculate that miR-186* is one of the pathways which curcumin induces apoptosis. Taken together, these results indicate that miR-186* may play an oncogenic role in human lung cancer cells.

We used the Miranda database to predict the target genes of miRNA-186*. Caspase-10 was indicated as one target gene of miR-186* by this prediction method. Caspase-10 was previously implicated in autoimmune lymphoproliferative syndrome and is an initiator caspase in death receptor signalling (42) that may be crucial for apoptotic signalling (43-45). Caspase-8, caspase-10 and caspase- 9 are believed to be the initiator caspases at the top of the caspase signalling cascade $(46,47)$. It has been recently reported that caspase-10 expression is downregulated in both rectal adenomas and cancers and may be involved in the pathogenesis of rectal cancer (48). Thus, we surmised that the increased expression of caspase-10 might play a key role in curcumin-induced A549 cell apoptosis. Our data demonstrate that caspase-10 is significantly increased after curcumin treatment of A549 cells (Fig. 5a). Moreover, manipulating the levels of miRNA-186* by transfection with oligonucleotides encoding it alters the expression of caspase-10 (Fig. 4). This manipulation of miRNA-186* levels also altered the protein levels of caspase-10 (Fig. 5b). Our study is the first to show that caspase-10 is an essential downstream target of miR-186*.

In conclusion, we report here the first evidence that miR-186* may be required for the anti-cancer effects of curcumin on the A549 human lung adenocarcinoma cell line. Furthermore, caspase-10 may be a critical target of miR-186* in preventing apoptosis. Our study reveals an important and novel mechanism by which curcumin inhibits cancer growth and induces apoptosis.

\section{Acknowledgements}

This study was supported by National Natural Science Foundation of China, Grant number: 30572359 and 81073107.

\section{References}

1. Jemal A, Siegel R, Ward E, Murray T, Xu J and Thun MJ: Cancer statistics. CA Cancer J Clin 56: 106-130, 2006.

2. Molina JR, Yang P, Cassivi SD, Schild SE and Adjei AA: Non-small cell lung cancer: epidemiology, risk factors, treatment, and survivorship. Mayo Clin Proc 83: 584-594, 2008.

3. Anthony HM, Madsen KE, Mason MK and Templeman GH: Lung cancer, immune status, histopathology and smoking. Is oat cell carcinoma lymphodependent? Br J Dis Chest 75: 40-54, 1981.

4. Anand P, Sundaram C, Jhurani S, Kunnumakkara AB and Aggarwal BB: Curcumin and cancer: an 'old-age' disease with an 'age-old' solution. Cancer Lett 18: 133-364, 2008.

5. Kuttan R, Bhanumathy P, Nirmala K and George MC: Potential anticancer activity of turmeric (Curcuma longa). Cancer Lett 29: $197-202,1985$. 
6. Sandur SK, Ichikawa H, Pandey MK, et al: Role of pro-oxidants and antioxidants in the anti-inflammatory and apoptotic effects of curcumin (diferuloylmethane). Free Radic Biol Med 43 568-580, 2007.

7. Singh S and Aggarwal BB: Activation of transcription factor NF-кB is suppressed by curcumin (diferuloylmethane). J Biol Chem 270: 24995-25000, 1995.

8. Hussain AR, Ahmed M, Al-Jomah NA, et al: Curcumin suppresses constitutive activation of nuclear factor-kappa B and requires functional Bax to induce apoptosis in Burkitt's lymphoma cell lines. Mol Cancer Ther 7: 3318-3329, 2008.

9. Mackenzie GG, Queisser N, Wolfson ML, Fraga CG, Adamo AM and Oteiza PI: Curcumin induces cell-arrest and apoptosis in association with the inhibition of constitutively active NF-kappaB and STAT3 pathways in Hodgkin's lymphoma cells. Int J Cancer 123: 56-65, 2008.

10. Chadalapaka G, Jutooru I, Chintharlapalli S, et al: Curcumin decreases specificity protein expression in bladder cancer cells. Cancer Res 68: 5345-5354, 2008

11. Lund E, Güttinger S, Calado A, Dahlberg JE and Kutay U: Nuclear export of miRNA precursors. Science 303: 95-98, 2004.

12. Kurihara Y and Watanabe Y: Arabidopsis micro-RNA biogenesis through Dicer-like 1 protein functions. Proc Nat Acad Sci USA 101: 12753-12758, 2004.

13. Roldo C, Missiaglia E, Hagan JP, et al: MiRNA expression abnormalities in pancreatic endocrine and acinar tumors are associated with distinctive pathologic features and clinical behavior. J Clin Oncol 24: 4677-4684, 2006.

14. Suzuki HI, Yamagata K, Sugimoto K, Iwamoto T, Kato S and Miyazono K: Modulation of miRNA processing by p53. Nature 460: 529-533, 2009

15. Takamizawa J, Konishi H, Yanagisawa K, et al: Reduced expression of the let-7 miRNAs in human lung cancers in association with shortened postoperative survival. Cancer Res 64 3753-3756, 2004.

16. Hayashita Y, Osada H, Tatematsu Y, et al: A polycistronic miRNA cluster, miR-17-92, is overexpressed in human lung cancers and enhances cell proliferation. Cancer Res 65 : 9628-9632, 2005

17. Wang QZ, Xu W, Habib N and Xu R: Potential uses of miRNA in lung cancer diagnosis, prognosis, and therapy. Curr Cancer Drug Targets 9: 572-594, 2009.

18. Mosmann T: Rapid colorimetric assay for cellular growth and survival: application to proliferation and cytotoxicity assays. J Immunol Methods 65: 55-63, 1983.

19. Lian J, Zhang X, Tian H, et al: Altered microRNA expression in patients with non-obstructive zoospermia. Reprod Biol Endocrinol 7: 13, 2009

20. Chen C, Ridzon DA, Broomer AJ, et al: Real-time quantification of miRNAs by stem-loop RT-PCR. Nucleic Acids Res 33: 179,2005

21. Li M, Zhang Z, Hill DL, Wang H and Zhang R: Curcumin, a dietary component, has anticancer, chemosensitization, and radiosensitization effects by down-regulating the MDM2 oncogene through the PI3K/mTOR/ETS2 pathway. Cancer Res 67: 1988-1996, 2007.

22. Schaaf C, Shan B, Buchfelder M, et al: Curcumin acts antitumourigenic and hormone-suppressive in murine and human pituitary tumour cells in vitro and in vivo. Endocr Relat Cancer 10: 1339-1345, 2009.

23. Zhou L, Qi X, Potashkin JA, Abdul-Karim FW and Gorodeski GI: MiRNAs miR-186 and miR-150 down-regulate expression of the pro-apoptotic purinergic $\mathrm{P} 2 \mathrm{X} 7$ receptor by activation of instability sites at the 3'-untranslated region of the gene that decrease steady-state levels of the transcript. J Biol Chem 17: 28274-28286, 2008

24. Qin LX, Beyer RP, Hudson FN, Linford NJ, Morris DE and Kerr KF: Evaluation of methods for oligonucleotide array data via quantitative real-time PCR. BMC Bioinformatics 17: 23-28, 2006

25. Lewis BP, Burge $\mathrm{Cb}$ and Bartel DP: Conserved seed paring, often flanked by adenosions, indicates that thousand of human genes are miRNA targets. Cell 120: 15-20, 2005.
26. Lim LP, Glasner ME, Yekta S, Burge CB and Bartel DP: Vertebrate miRNA genes. Science 299: 1540, 2003.

27. Berezikov E, Guryev V, van de Belt J, Wienholds E, Plasterk RH and Cuppen E: Phylogenetic shadowing and computational identification of human miRNA genes. Cell 120: 21-24, 2005.

28. Li SC, Tang P and Lin WC: Intronic miRNA: discovery and biological implications. DNA Cell Biol 26: 195-207, 2007.

29. Xia L, Zhang D, Du R, et al: miR-15b and miR-16 modulate multidrug resistance by targeting BCL2 in human gastric cancer cells. Int J Cancer 123: 372-379, 2008

30. Kakar SS and Roy D: Curcumin inhibits TPA induced expression of c-fos, c-jun and c-myc proto-oncogenes messenger RNAs in mouse skin. Cancer Lett 87: 85-89, 1994.

31. Camacho-Barquero L, Villegas I, Sánchez-Calvo JM, et al: Curcumin, a Curcuma longa constituent, acts on MAPK p38 pathway modulating COX-2 and iNOS expression in chronic experimental colitis. Int Immunopharmacol 7: 333-342, 2007.

32. Shankar S and Srivastava RK: Involvemet of Bcl-2 famliy members, phosphatidylinositol 3'-kinase/AKT and mitochondrial p53 in curcumin(diferuloymethane)-induced apoptosis in prostate cancer. Int J Oncol 30: 905-918, 2007.

33. Sun M, Estrov Z, Ji Y, Coombes KR, Harris DH and Kurzrock R: Curcumin (diferuoymethane) alters the expression profiles of miRNAs in human pancreatic cancer cells. Mol Cancer Ther 7: 464-743, 2008.

34. Nana-Sinkam SP and Geraci MW: MiRNA in lung cancer. J Thorac Oncol 1: 929-931, 2006.

35. Raponi M, Dossey L, Jatkoe T, et al: MiRNA classifiers for predicting prognosis of squamous cell lung cancer. Cancer Res 69: 5776-5832, 2009

36. Chin LJ, Ratner E, Leng S, et al: A SNP in a let-7 miRNA complementary site in the KRAS 3 ' untranslated region increases non-small cell lung cancer risk. Cancer Res 68: 8535-8540, 2008.

37. Esquela-Kerscher A, Trang P, Wiggins JF, et al: The let-7 miRNA reduces tumor growth in mouse models of lung cancer. Cell Cycle 7: 759-764, 2008.

38. Ortholan C, Puissegur MP, Ilie M, Barbry P, Mari B and Hofman P: MiRNAs and lung cancer: new oncogenes and tumor suppressors, new prognostic factors and potential therapeutic targets. Curr Med Chem 16: 1047-1061, 2009.

39. Yanaihara N, Caplen N, Bowman E, et al: Unique miRNA molecular profiles in lung cancer diagnosis and prognosis. Cancer Cell 9: 189-198, 2006.

40. Giard DJ, Aaronson SA and Todaro GJ: In vitro cultivation of human tumors: establishment of cell lines derived from a series of solid tumors. J Natl Cancer Inst 51: 1417-1423, 1973.

41. Radhakrishna Pillai G, Srivastava AS, Hassanein TI, Chauhan DP and Carrier E: Induction of apoptosis in human lung cancer cells by curcumin. Cancer Lett 208: 163-170, 2004.

42. Wang J, Chun HJ, Wong W, Spencer DM and Lenardo MJ: Caspase-10 is an initiator caspase in death receptor signaling. Proc Natl Acad Sci USA 98: 13884-13888, 2001.

43. Wang J, Zheng L, Lobito A, et al: Inherited human caspase-10 mutations underlie defective lymphocyte and dendritic cell apoptosis in autoimmune lymphoproliferative syndrome type II. Cell 98: 47-58, 1999.

44. Nohara K, Yokoyama Y and Kano K: The important role of caspase-10 in sodium butyrate-induced apoptosis. Kobe J Med Sci 53: 265-273, 2007

45. Lee HJ, Pyo JO, Oh Y, et al: AK2 activates a novel apoptotic pathway through formation of a complex with FADD and caspase-10. Nat Cell Biol 9: 1303-1310, 2007.

46. Chen $\mathrm{M}$ and Wang $\mathrm{J}$ : Initiator caspases in apoptosis signaling pathways. Apoptosis 7: 313-319, 2002.

47. Micheau O and Tschopp J: Induction of TNF receptor Imediated apoptosis via two sequential signaling complexes. Cell 114: 181-190, 2003.

48. Xu B, Zhou ZG, Li Y, Wang L, Yang L, Zhou B, Liu HY, Song JM, Zeng YJ, Wang R, Shen XG and Sun XF: Clinicopathological significance of caspase- 8 and caspase-10 expression in rectal cancer. Oncology 74: 229-236, 2008. 